\title{
CASE OF THE MONTH
}

\section{A child with skin nodules and extensive soft tissue calcification}

\author{
N S CHAUHAN, MD and Y P SHARMA, MD
}

Department of Radiodiagnosis, Dr Rajendra Prasad Government Medical College, Himachal Pradesh, India

\author{
Received 8 February 2011 \\ Revised 18 April 2011 \\ Accepted 4 May 2011 \\ DOI: $10.1259 / \mathrm{bjr} / 95392214$ \\ (C) 2012 The British Institute of \\ Radiology
}

\section{Case history}

A 9-year-old male presented to the dermatology clinic complaining of hard cutaneous nodules all over his body. The patient also had a chronic history of proximal muscle weakness of approximately 5 years' duration. On examination some of the nodules were whitish in colour and a white-coloured liquid discharge was seen exuding from the left calf skin surface. Multiple plaques were identified over the extensor surface of the hands, especially over the

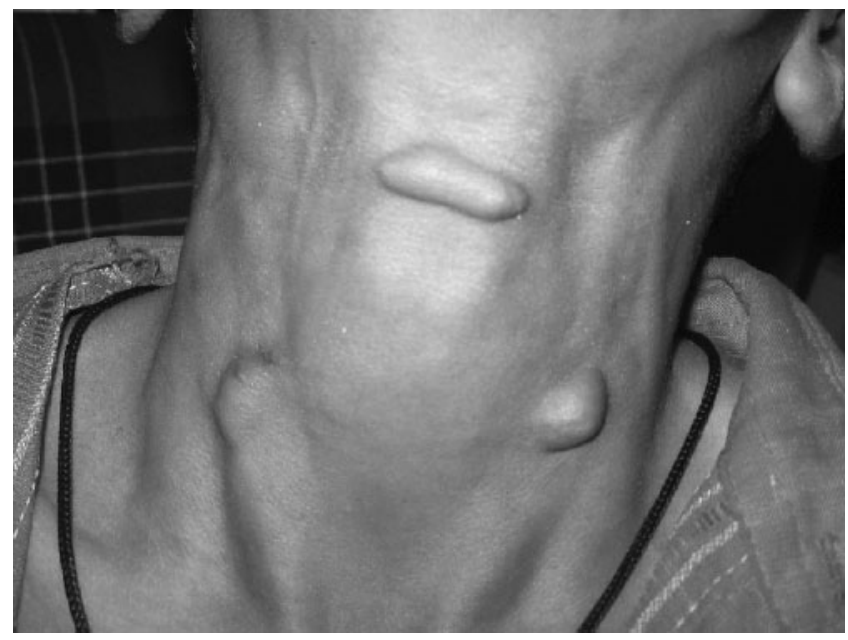

Figure 1. Photograph of the patient showing the cutaneous nodules in the neck region.

Address correspondence to: Dr Narvir Singh Chauhan, Set No A 3, Type IV Quarters, Dr Rajendra Prasad Government Medical College Campus, Tanda, Kangra, Himachal Pradesh 176001, India. E-mail: narvirschauhan@yahoo.com knuckles. There was no family history of a similar disease. The patient had two older brothers who were both healthy. Radiographs of the upper and lower extremities were requested. A CT of the lower extremities was also performed after a few days.

What do you notice in Figures 1 and 2?

Can you see a pattern in Figure 3?

What additional findings can be observed in Figures 4-6?

What is your diagnosis?

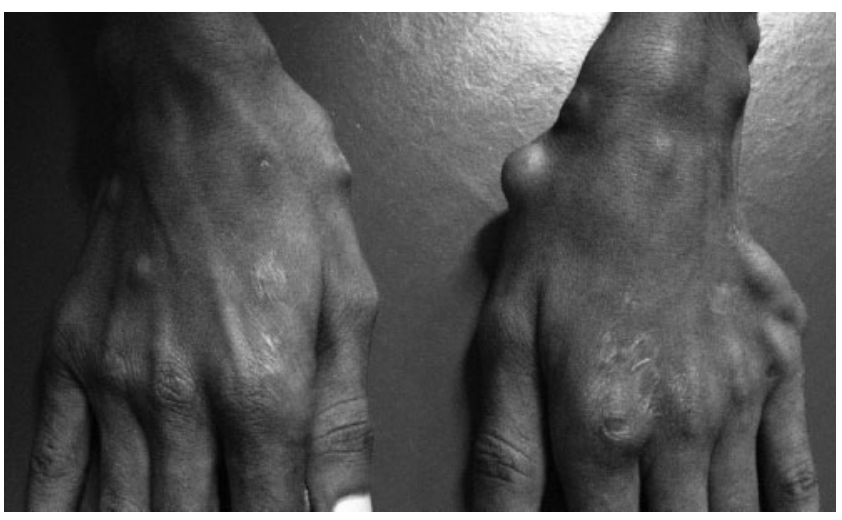

Figure 2. Photograph of both hands showing plaque-like lesions over the extensor aspects of hands and the knuckles. A few cutaneous nodules are also seen. 


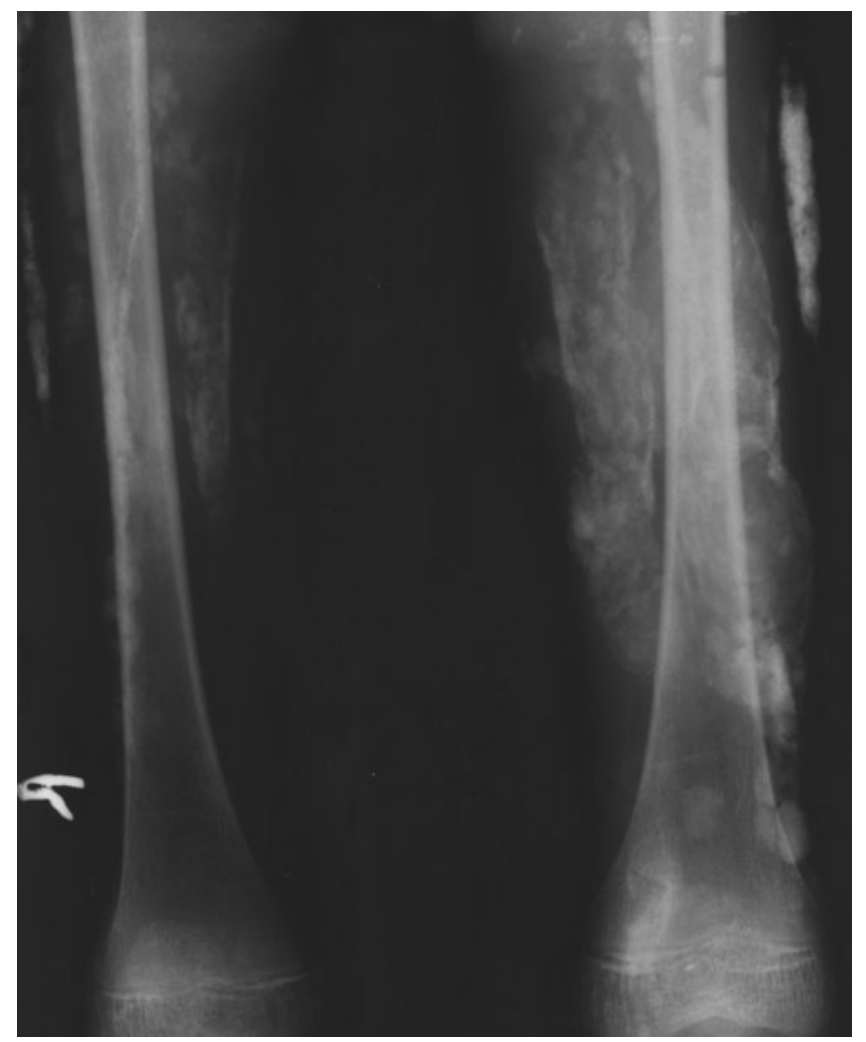

Figure 3. Radiograph of both thighs showing a typical sheet-like pattern of soft tissue calcification along the muscular planes and subcutaneous fascia.

\section{Diagnosis}

The distinctive pattern of diffuse soft tissue calcification in subcutaneous and muscular planes occurs in calcinosis universalis. The condition may be idiopathic or due to a connective tissue disorder, for example systemic lupus erythematosus, scleroderma and juvenile dermatomyositis (JDM). Biochemical tests can help to narrow the differential diagnoses.

In our patient, muscle enzyme levels were found to be markedly elevated with serum creatine phosphokinase and aldolase levels at $613 \mathrm{U} \mathrm{l}^{-1}$ and $29 \mathrm{Ul}^{-1}$, respectively (the normal range for creatine phosphokinase is

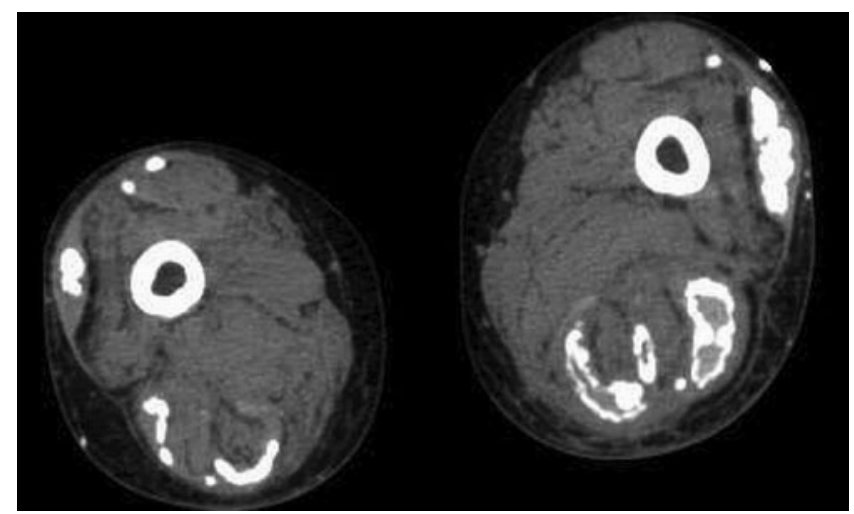

Figure 4. Axial CT image of the bilateral thigh region confirming the extensive calcification within the muscle planes. Additionally, smaller nodular areas of calcification are also identified in the subcutaneous tissues.

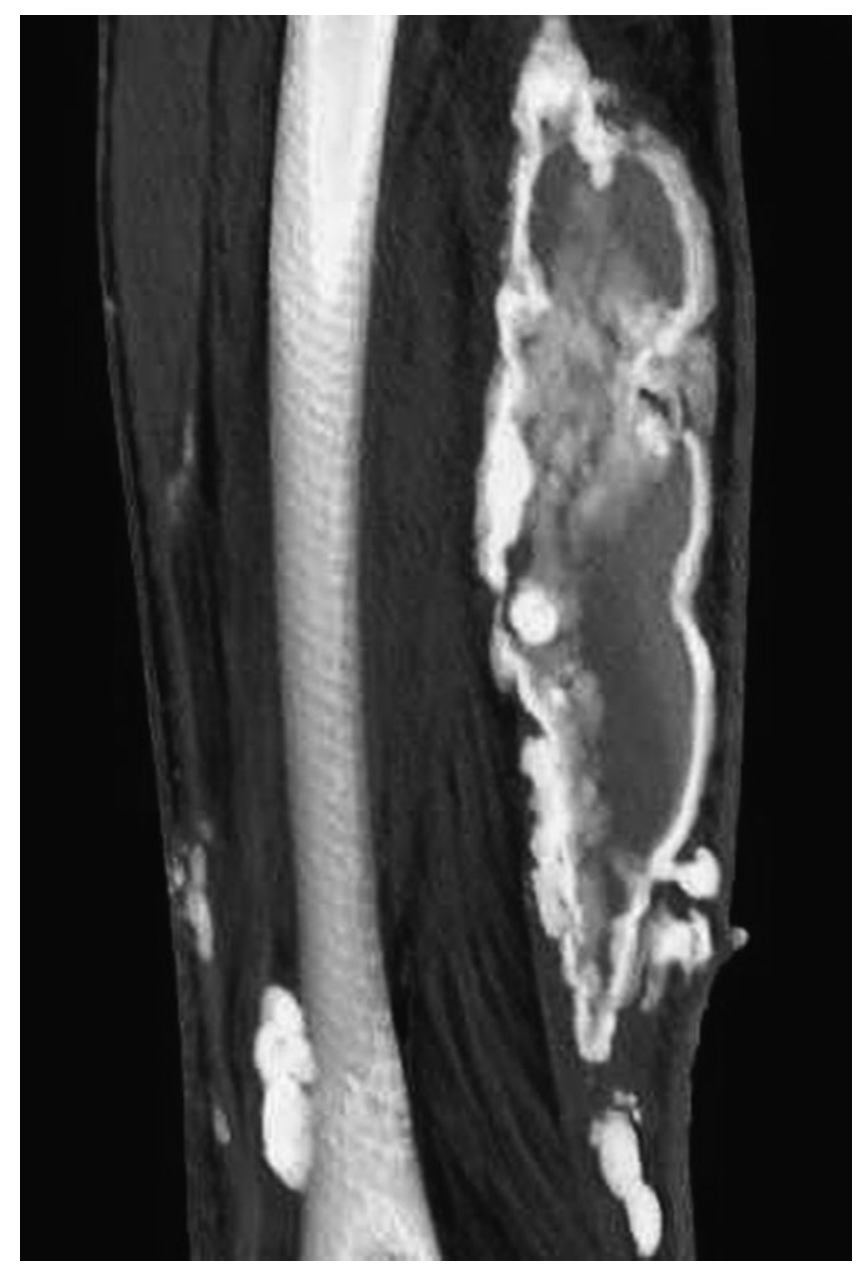

Figures 5. Sagittal volume-rendered CT images of the left thigh showing the large intramuscular pockets of liquefied calcium with layering of calcium. One of the intramuscular pockets of liquid calcium is actively oozing calcium through the skin surface.

60-170 $\mathrm{U}^{-1}$ and for aldolase is $0-6 \mathrm{U} \mathrm{l}^{-1}$ ). The antinuclear antibody test was negative; serum calcium and phosphorus levels were within the normal range. The ultrasound of the abdomen was also normal. The patient history did not reveal any complaints characteristic of Raynaud's phenomenon or of scleroderma. On review of the dermatology, the plaque-like lesions on the extensor aspect of the hands were diagnosed as Gottron's papules. Correlation of the radiological findings, clinical evaluation and biochemistry in our patient suggested that JDM was the underlying disease and ruled out other diseases such as systemic lupus erythematosus and scleroderma. Inherited disorders, such as Ehlers-Danlos syndrome and pseudoxanthoma elasticum, in which the dystrophic soft tissue calcifications may resemble calcinosis universalis, were also not considered because features such as hypermobility of skin or laxity of joints, which are present in these disorders, were not seen in our patient.

\section{Discussion}

Calcinosis universalis refers to dystrophic calcification occurring in a diffuse sheet-like manner in the fascial 


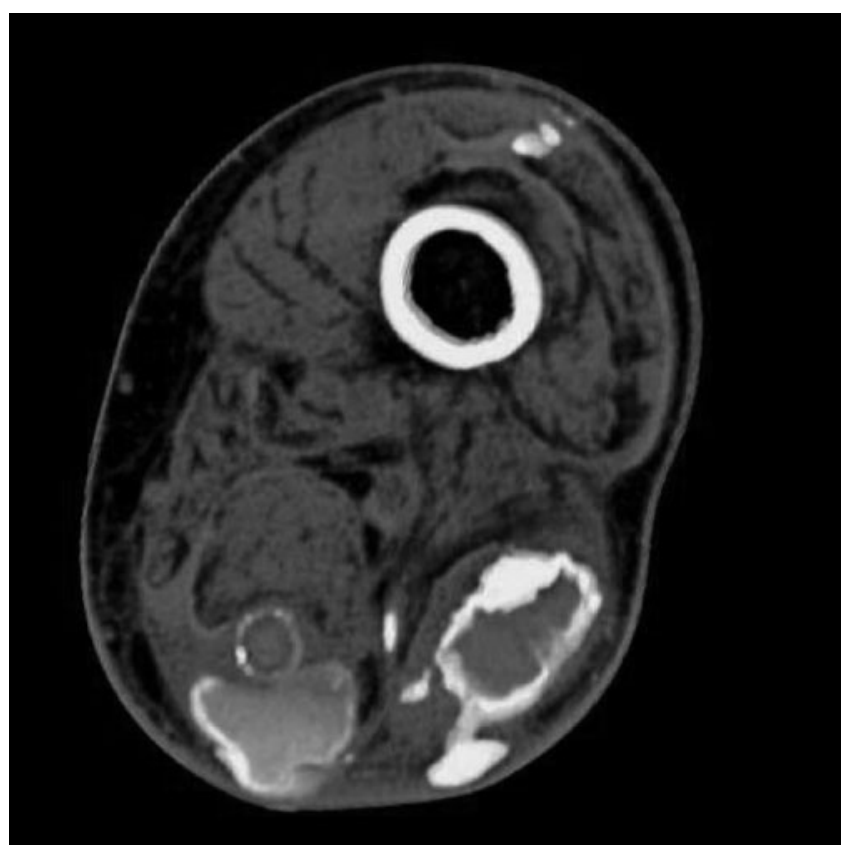

Figure 6. Axial volume-rendered CT images of the left thigh showing the large intramuscular pockets of liquefied calcium with layering of calcium. One of the intramuscular pockets of liquid calcium is actively oozing calcium through the skin surface.

planes, subcutaneous tissues and muscles. It is commonly seen in association with connective tissue disease, e.g. polymyositis or dermatomyositis. JDM is the childhood form of dermatomyositis and is a rare multisystem autoimmune disease of unknown aetiology, characterised by inflammatory myopathy. The incidence is two to three cases per million children per year [1]. The presence of skin rashes such as Gottron's papule and heliotrope rash is considered characteristic of JDM. Calcinosis, the hallmark of JDM, is seen in $30 \%$ of patients, with a prevalence range of $10-50 \%[2,3]$. Calcification is dystrophic and serum calcium and phosphorus levels are normal. Four different patterns of calcifications have been described in patients with JDM [3, 4]:

1. superficial plaques or nodules in skin and subcutaneous tissues

2. deep nodular deposits extending to muscles

3. deposits along fascial planes of muscles and tendons

4. hard deposits covering the entire body surface.

The incidence for patterns $1-4$ is $33 \%, 20 \%, 16 \%$ and $10 \%$, respectively [5]. In $22 \%$ of patients a mixed pattern is seen. The sites most frequently involved are the elbows, knees, digits and extremities. Commonly, the time period for the appearance of calcinosis after the onset of the illness is $1-3$ years, but it can be as long as 20 years. Imaging with conventional radiography can identify the pattern of soft tissue calcification and aid the diagnosis. CT is more sensitive and specific than conventional radiography for deeper soft tissue calcifications [6]. CT also has the advantage of depicting ossifying lesions and the plane of calcification. MRI sequences, for example short tau inversion-recovery, may be useful in picking up oedema or inflammation of the skin, subcutaneous tissues or fascia prior to the development of calcinosis.

Risk factors for the development of calcinosis are poorly understood, but it has been associated with a delay in diagnosis and the initiation of therapy. The natural course of calcinosis is variable and unpredictable, and a number of sequelae may be seen. Spontaneous extrusion or reabsorption may sometimes lead to regression. Improvement is more likely in those patients with inactive disease, those who engage in more physical activity, those with superficial plaques or nodules rather than deep deposits and those treated with an aggressive therapeutic regimen [3]. Radiologists can play an important role by aiding the diagnosis of this rare disease and paving the way for early initiation of therapy and, possibly, a favourable outcome. Other causes of soft tissue calcification include metastatic calcification (due to hyper- or hypoparathyroidism, paraneoplastic hypercalcaemia, excessive vitamin D or milk alkali syndrome), dystrophic calcifications in inherited disorders (Ehlers-Danlos or pseudoxanthoma elasticum), soft tissue tumour, gout, parasitic infections or idiopathic tumoural calcinosis [1]. Correlation of the typical radiological patterns of soft tissue calcification with biochemical tests (elevated muscle enzyme levels with normal serum calcium and phosphorus levels) and the presence of skin lesions help in achieving the correct diagnosis of JDM and in excluding other conditions.

\section{Conclusion}

Calcinosis universalis has unique and typical radiological findings, and the possibility of a rare disorder such as JDM should be considered as the underlying cause if the patient is a child and the biochemical tests and clinical picture are also suggestive.

\section{Acknowledgments}

Thank you to the parents of the patient for their informed consent to use the photograph and their voluntary participation in this study.

\section{References}

1. Agarwal V, Sachdev A, Dabra A K. Case 104: Calcinosis in juvenile dermatomyositis. Radiology 2007;242:307-11.

2. Fisler RE, Liang MG, Fuhlbrigge RC, Yalcindag A, Sundel RP. Aggressive management of juvenile dermatomyositis results in improved outcome and decreased incidence of calcinosis. J Am Acad Dermatol 2002;47:505-11.

3. Rider LG. Calcinosis in juvenile dermatomyositis: pathogenesis and current therapies. Pediatric Rheumatology Online Journal 2003;1:119-33.

4. Blane CE, White SJ, Braunstein EM, Bowyer SL, Sullivan DB. Patterns of calcification in childhood dermatomyositis. Am J Roentgenol 1984;142:397-400.

5. Bowyer SL, Blane CE, Sullivan DB, Cassidy JT. Childhood dermatomyositis: Factors predicting functional outcome and development of dystrophic calcification. J Pediatr 1983;103:882-8.

6. Fishel B, Diamant S, Papo I, Yaron M. CT assessment of calcinosis in a patient with dermatomyositis. Clin Rheumatol 1986;5:242-4. 